\title{
Periorbital edema secondary to imatinib mesylate
}

This article was published in the following Dove Press journal:

Clinical Ophthalmology

II May 2010

Number of times this article has been viewed

\section{Collin M McClelland \\ George J Harocopos Philip L Custer \\ School of Medicine, Washington \\ University, St. Louis, MO, USA}

Correspondence: Collin McClelland Washington University School of Medicine, Campus Box 8096, 660 South Euclid Ave, St. Louis, MO, 63110-1093, USA
Abstract: Imatinib mesylate $\left(\right.$ Gleevec $\left.^{\circledR}\right)$ is a well-established pharmacologic treatment for all phases of chronic myeloid leukemia and for advanced gastrointestinal stromal tumors (GISTs). Edema-related side effects are relatively common in imatinib therapy with the periocular skin representing one of the most common sites for localized edema. While the adverse effect of periorbital edema with imatinib is well documented in the oncology literature, there is limited reference to this common reaction in the ophthalmology literature. We report two patients with upper eyelid edema associated with imatinib therapy who required surgical intervention to ameliorate significant visual field obstruction. We highlight the details of each case including the histopathologic findings of excised redundant skin followed by a thorough review of the literature on imatinib related periorbital edema.

Keywords: imatinib mesylate, gleevec, edema, periorbital edema, tyrosine kinase inhibitor

\section{Introduction}

Imatinib mesylate $\left(\right.$ Gleevec $\left.^{\circledR}\right)$ is a well-established pharmacologic treatment for all phases of chronic myeloid leukemia (CML) and for advanced gastrointestinal stromal tumors (GISTs). ${ }^{1-3}$ Mechanisms of action include selective inhibition of several tyrosine kinases, including the bcr-abl fusion protein in CML and the c-kit proto-oncogene in GIST., ${ }^{2,4}$ The most frequently reported side effects include nausea/ vomiting, musculoskeletal pain, diarrhea, fatigue, rash, and edema. The eyelids and periocular skin are one of the most common areas where localized edema may arise, but edema may regularly occur elsewhere, including the lower extremities and face. Severe generalized fluid retention, pulmonary edema, pericardial effusion, pleural effusion, cerebral edema, ascites, or anasarca is rare. ${ }^{5,6}$ Other serious side effects are also relatively uncommon, including Stevens-Johnson syndrome, hemolytic anemia, internal hemorrhage, and hepatotoxicity. ${ }^{7,8}$ Additional rare ocular side effects have been reported, including cystoid macular edema, optic disc edema, and macular ischemia. $^{9-12}$

While the adverse effect of periorbital edema with imatinib is well documented in the oncology literature, there is limited reference to this common reaction in the ophthalmology literature. ${ }^{13-15}$ The eyelid edema is typically mild, worse in the morning, and is not an indication for cessation of imatinib therapy. ${ }^{16}$ In only two previously reported cases was the edema severe enough to require surgical intervention. ${ }^{15,16}$

We report two patients with upper eyelid edema associated with imatinib therapy. Both patients required surgical intervention to ameliorate significant visual field obstruction. With only two previous sources in the literature describing the histopathology of 
imatinib-induced edema, ${ }^{15,16}$ the histopathology of these cases is reviewed, including findings of lymphangiectasia not reported previously.

\section{Case report I}

A 64-year-old Caucasian female was referred to our oculoplastics service for a recent exacerbation of long-standing periorbital swelling. She had been diagnosed with CML 10 years previously, and developed mild upper eyelid swelling immediately following initiation of imatinib treatment several years prior to presentation. Four months prior to referral to us, the patient's dose of imatinib was increased from 400 to $600 \mathrm{mg}$ per day in order to induce remission of accelerated CML. Several weeks following the increase in her imatinib dose, the patient reported severe periorbital swelling, ocular heaviness, frequent bilateral ocular discharge with irritation, and occasional morning diplopia lasting several hours that she observed to be correlated with her degree of swelling. Two weeks before our evaluation, she remitted to the chronic phase of CML, and her dose of imatinib was decreased to $500 \mathrm{mg}$ per day, with a minor improvement in symptoms.

External examination (Figure 1A) revealed bilateral ptosis with a margin-reflex distance (MRD) of $1 \mathrm{~mm}$ OD and $0.5 \mathrm{~mm} \mathrm{OS}$, significantly edematous upper eyelid skin, normal levator function of $17 \mathrm{~mm}$ OU, no lagophthalmos, and angular blepharitis in the left lateral canthus. Visual acuity was 20/25 - 2 OD and 20/40 + 2 OS. Pupils, motility, slit-lamp, tonometry, and funduscopic examination findings were unremarkable.

We prescribed erythromycin ointment for blepharitis and advised the patient to follow up in clinic for re-evaluation, realizing a potential for greater improvement in symptoms following the recent decrease in her imatinib dosage. Upon her return to clinic six weeks later, the patient reported little relief of visual obstruction or irritation. Goldmann ptosis visual fields performed at that time demonstrated significant superior visual field obstruction to $10^{\circ} \mathrm{OD}$ and $17^{\circ} \mathrm{OS}$, with improvement to $38^{\circ} \mathrm{OD}$ and $41^{\circ} \mathrm{OS}$ with manual elevation of the upper eyelids.

With the patient's CML maintained on imatinib therapy and little relief of ocular symptoms following dose reduction, the decision was made to proceed with bilateral upper eyelid blepharoplasty. At her one-month post-operative appointment, the patient reported a dramatic improvement in ocular irritation, ocular discharge, morning diplopia, and superior field vision obstruction. Examination showed well-healed incisions and marked improvement in eyelid appearance (Figure 1B). During a telephone interview

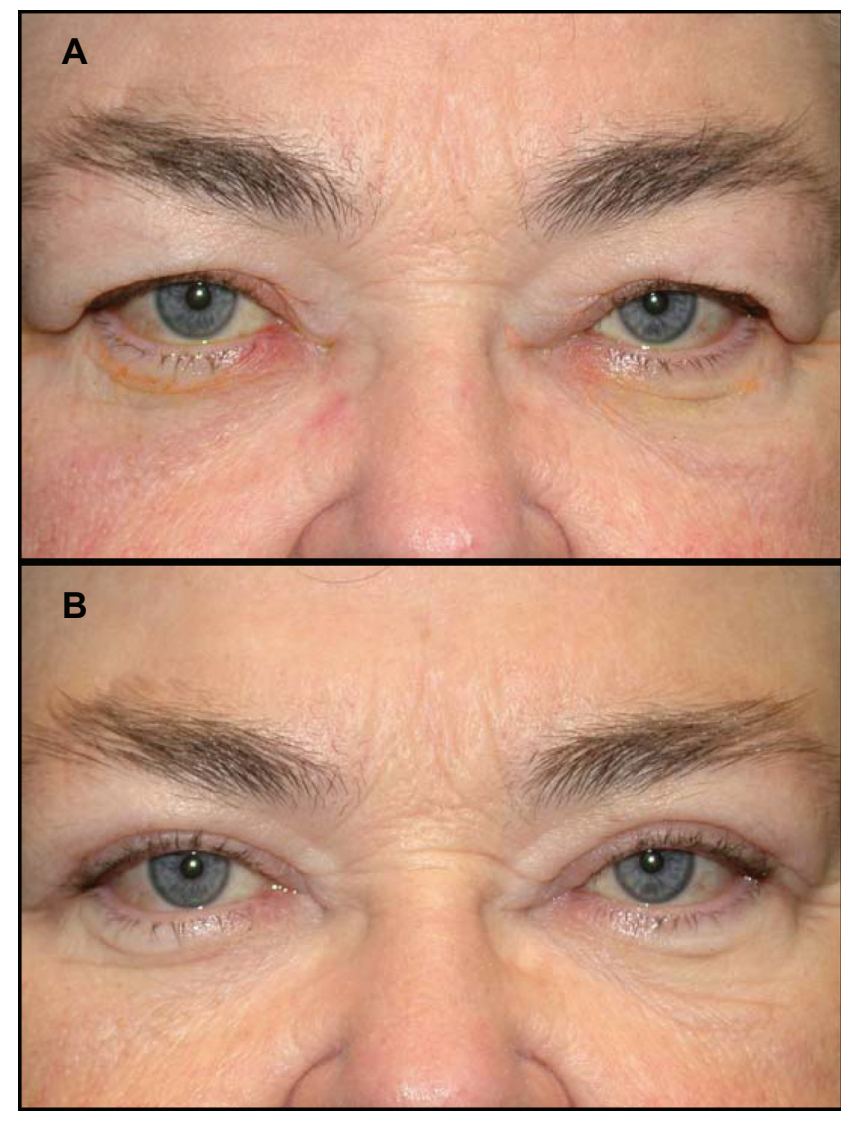

Figure I A External photograph of patient I preoperatively, demonstrating significant upper eyelid edema bilaterally, associated with imatinib therapy. B One-month postoperative photograph, showing marked improvement in eyelid appearance following blepharoplasty.

50 months following surgery, the patient reported only mild periorbital swelling without visual significance, and she continues on imatinib $600 \mathrm{mg}$ daily.

Microscopic examination of the two excised specimens of upper eyelid tissue (Figure 2) exhibited edema and chronic inflammation, consistent with the histopathology of imatinibinduced eyelid edema previously reported. ${ }^{15,16}$ The inflammation bore an apparent affinity for perifollicular regions. Lymphangiectasia was also noted.

\section{Case report 2}

A 66-year-old Caucasian male was referred to our oculoplastic service for slow progression of chronic eyelid swelling that he had first noticed five years previously following initiation of imatinib for advanced GIST with metastasis to the liver. The patient ultimately sought oculoplastic evaluation because he began frequently "bumping his head" as a result of severe superior field vision obstruction. The patient denied ocular discharge, epiphora, or diplopia. At the time of presentation, his imatinib dose was $600 \mathrm{mg}$ per day. 



Figure 2 Histopathology of excised eyelid skin (H\&E stain). A: Low-power view showing diffuse edema in the dermis (magnification, x20). B:At higher magnification (x200), dilated lymphatic channels (lymphangiectasia, double-headed arrows) may be appreciated. Mixed chronic inflammatory cells (block arrow) are seen, much of the inflammation occurring adjacent to hair follicles (arrows). C: Higher magnification (x600) of the area outlined by the rectangle in B).

Abbreviation: H\&E, hematoxylin \& eosin.

On examination, the patient had marked bilateral upper eyelid ptosis and edema (Figure 3A). MRD measured $1.5 \mathrm{~mm}$ OD and $2 \mathrm{~mm}$ OS, with normal levator functions of $17 \mathrm{~mm}$ OD and $16 \mathrm{~mm}$ OS. With the exception of mild cataracts OU, the remainder of the examination was unremarkable. Goldmann ptosis visual fields exhibited severe superior visual field obstruction to $-16^{\circ} \mathrm{OD}$ and $-13^{\circ}$ OS that improved to $32^{\circ}$ OD and $33^{\circ}$ OS with manual elevation.

Considering his requirement to continue imatinib therapy and the severity of his visual field obstruction, the patient opted to undergo bilateral upper eyelid blepharoplasty with ptosis repair. At his one-month postoperative follow-up, the patient reported dramatic improvement in vision, periocular swelling, and overall ocular comfort. Examination revealed well-positioned eyelid margins, no lagophthalmos, and mild residual edema of the left upper eyelid (Figure 3B). During a telephone interview 52 months following surgery the patient reported no residual periorbital edema and continues on imatinib $600 \mathrm{mg}$ daily.

Microscopic examination of the resected eyelid tissue showed findings identical to those observed in case report 1 .

\section{Discussion}

Early Phase I and II trials of imatinib for CML and GIST, along with subsequent studies examining the side effects of imatinib, report incidence rates of edema in the range of $39 \%-74.1 \%$ in all patients on the medication..$^{1,2,4,13,17}$ Results specifying edema location report the periocular region as the most common site of edema, present in $47.6 \%-70 \%$ of patients taking imatinib., ${ }^{2,13,17}$ The causal role of imatinib in periorbital edema is strongly suggested by the high frequency of this side effect and the well-documented resolution of periorbital edema in 12 patients following cessation of the drug as a result of severe myelosuppression. ${ }^{13}$ When rechallenged with equivalent or reduced doses of imatinib 


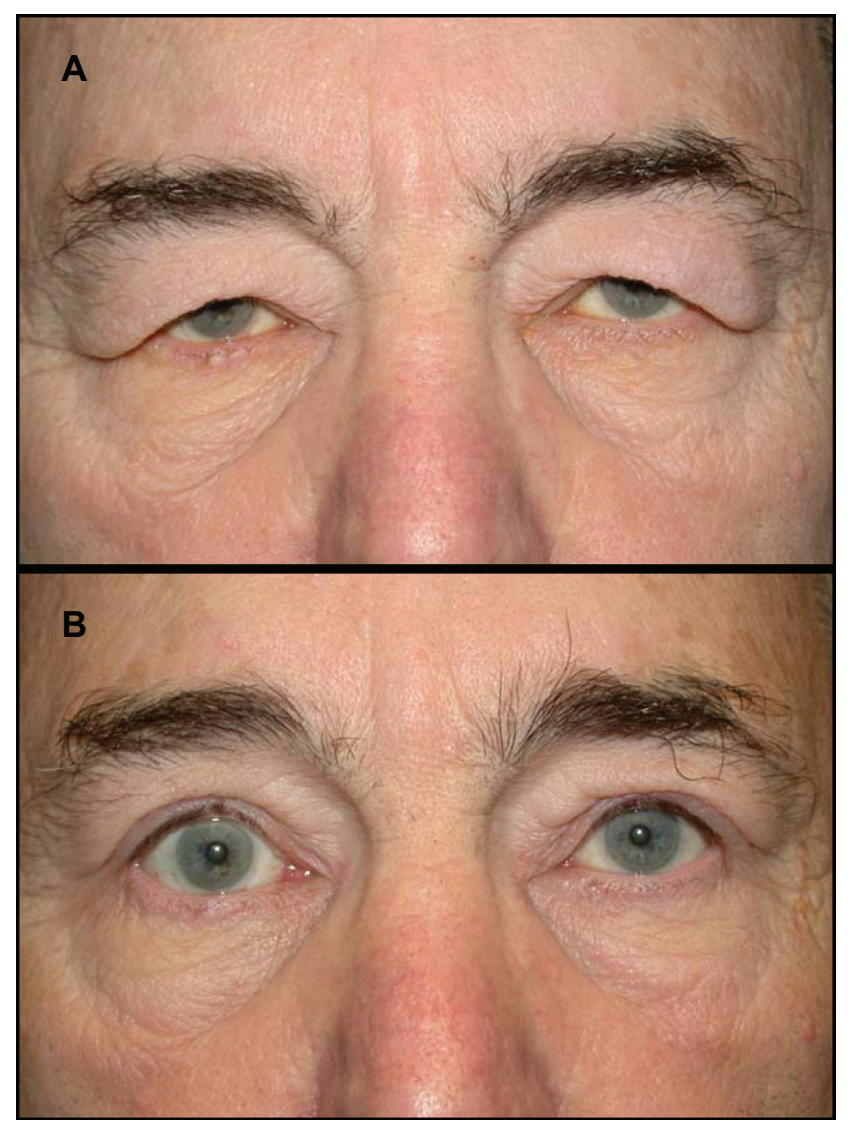

Figure 3 A External photograph of patient 2 preoperatively, demonstrating significant upper eyelid edema bilaterally. B One month postoperative external photograph, showing marked improvement in eyelid appearance following blepharoplasty and ptosis repair.

after bone marrow recovery, periorbital edema recurred in eight of the 12 patients.

Valeyrie et $\mathrm{a}{ }^{17}$ found that the mean dose of imatinib among patients suffering fluid retention events (471 \pm $113 \mathrm{mg}$ ) was significantly greater than the mean dose among patients without edema $(395 \pm 108 \mathrm{mg})$. Throughout the literature, the frequency of edema related to imatinib appears to be dose-related. Fraunfelder et $\mathrm{al}^{13}$ reported that 10 of 11 patients $(91 \%)$ treated with imatinib doses $>400 \mathrm{mg}$ developed periorbital edema, compared with only 66 of 94 patients $(70 \%)$ treated with doses $<400 \mathrm{mg}$. Our patients were both on a dose of $600 \mathrm{mg}$ per day at the time of presentation. In a series reported by Fraunfelder, ${ }^{13}$ the onset of periorbital edema occurred at an average of $68 \pm$ 48 days after initiation of treatment (range 1-444 days), and no statistically significant correlation was found between dose and time of onset. Although it has been suggested that female sex and age $>65$ years are risk factors for fluid retention and may predispose to imatinib-induced edema, ${ }^{5}$ Valeyrie et al ${ }^{17}$ found no significant associations between age, sex, and the incidence of edema attributable to imatinib.

Although the mechanism for imatinib-induced periorbital edema remains unclear, the most popular theory involves the inhibition of platelet-derived growth factor receptor (PDGFR) signaling by the drug. PDGFR signaling has been shown to increase the interstitial fluid pressure in the dermis of rodents. ${ }^{18}$ The inhibition of the PDGFR signaling cascade by imatinib in human patients may similarly result in increased capillary permeability and extravasation of fluid. Preferred localization of edema to the periorbital skin is not likely to be explained exclusively by this theory, considering only $29 \%$ of patients with periorbital edema suffered from concomitant peripheral edema. ${ }^{13}$ It has been suggested that the dense collagenous orbital septum and poorly developed lymphatic system of the orbit predispose this region to edema. ${ }^{16}$ However, imaging studies in patients with imatinib-induced periorbital edema show the edema to be predominantly isolated to the preseptal region, which would suggest that the absence of orbital lymphatics may not be relevant in edema formation. In two previously reported cases showing histopathology of imatinib-induced eyelid edema, findings included loose dermis along with mild acute and chronic inflammation. ${ }^{15,16}$ In our cases, we found the inflammation to have an affinity for hair follicles, and we also found lymphangiectasia. Although nonspecific, lymphangiectasia correlates with the edema seen clinically.

Periorbital edema secondary to imatinib is typically mild to moderate and can usually be managed conservatively. While there is little scientific data to guide physicians, severe cases of periorbital edema have been treated by various means, including prescribing a low-salt diet, topical 1\% hydrocortisone, $0.25 \%$ topical phenylephrine, or oral diuretics. ${ }^{5,6}$ Severe periorbital edema is not an indication for cessation of imatinib. For cases of visually obstructive periorbital edema refractory to medical management, surgery remains a viable option. In our cases and the previous cases of imatinibinduced periorbital edema requiring surgery, satisfactory outcomes were sustained throughout the follow-up period, without recurrence of significant edema despite continuation of imatinib therapy. ${ }^{15,16}$ Follow-up in previously published cases requiring surgery was 17 months and six months, while our patients reported no significant recurrence of periorbital swelling at 50 and 52 months postoperatively.

Because of the risk of relapse, it is currently recommended that imatinib therapy be continued indefinitely in patients with CML. ${ }^{19}$ Given that imatinib is used for all phases of CML, as well as the growing use of imatinib for GIST and in a variety of dermatologic conditions, ${ }^{2,3,7}$ an increasing prevalence of 
imatinib-induced periorbital edema may be expected in the future. The ophthalmologic community should be cognizant of this relatively common side effect.

\section{Disclosures}

The authors report no conflict of interest in this work.

\section{References}

1. Druker BJ, Sawyers CL, Kantarjian H, et al. Activity of a specific inhibitor of the BCR-ABL tyrosine kinase in the blast crisis of chronic myeloid leukemia and acute lymphoblastic leukemia with the Philadelphia chromosome. N Engl J Med. 2001;344(14):1038-1042.

2. Demetri GD, von Mehren M, Blanke CD, et al. Efficacy and safety of imatinib mesylate in advanced gastrointestinal stromal tumors. $N$ Engl J Med 2002;347(7):472-480.

3. Cohen MH, Johnson JR, Pazdur R. US Food and Drug Administration Drug Approval Summary: Conversion of imatinib mesylate (STI571; Gleevec) tablets from accelerated approval to full approval. Clin Cancer Res. 2005;11(1):12-19.

4. Druker BJ, Talpaz M, Resta DJ, et al. Efficacy and safety of a specific inhibitor of the BCR-ABL tyrosine kinase in chronic myeloid leukemia. N Engl J Med. 2001;344(14):1031-1037.

5. Deininger MW, O’Brien SG, Ford JM, Druker BJ. Practical management of patients with chronic myeloid leukemia receiving imatinib. J Clin Oncol. 2003;21(8):1637-1647.

6. Guilhot F. Indications for imatinib mesylate therapy and clinical management. Oncologist. 2004;9(3):271-281.

7. Scheinfeld N. A comprehensive review of imatinib mesylate (Gleevec) for dermatological diseases. J Drugs Dermatol. 2006;5(2):117-22.

8. Scheinfeld N. Imatinib mesylate and dermatology Part 2: A review of the cutaneous side effects of imatinib mesylate. J Drugs Dermatol. 2006;5(3):228-231.

9. Masood I, Negi A, Dua HS. Imatinib as a cause of cystoid macular edema following uneventful phacoemulsification surgery. $J$ Cataract Refract Surg. 2005;31(12):2427-2428.

Clinical Ophthalmology

\section{Publish your work in this journal}

Clinical Ophthalmology is an international, peer-reviewed journal covering all subspecialties within ophthalmology. Key topics include: Optometry; Visual science; Pharmacology and drug therapy in eye diseases; Basic Sciences; Primary and Secondary eye care; Patient Safety and Quality of Care Improvements. This journal is indexed on

Submit your manuscript here: http://www.dovepress.com/clinical-ophthalmology-journal
10. Georgalas I, Pavesio C, Ezra E. Bilateral cystoid macular edema in a patient with chronic myeloid leukaemia under treatment with imanitib mesylate: Report of an unusual side effect. Graefes Arch Clin Exp Ophthalmol. 2007;245(10):1585-1586.

11. Kwon SI, Lee DH, Kim YJ. Optic disc edema as a possible complication of Imatinib mesylate (Gleevec). Jpn J Ophthalmol. 2008;52(4): 331-333.

12. Roth D, Akbari S, Rothstein A. Macular ischemia associated with imatinib mesylate therapy for chronic myeloid leukemia. Retin Cases Brief Rep. 2009;3(2):161-164.

13. Fraunfelder FW, Solomon J, Druker BJ, et al. Ocular side-effects associated with imatinib mesylate (Gleevec). J Ocul Pharmacol Ther. 2003;19(4):371-375.

14. Esmaeli B, Diba R, Ahmadi MA, et al. Periorbital oedema and epiphora as ocular side effects of imatinib mesylate (Gleevec). Eye 2004;18(7):60-62.

15. Larson JS, Bergstrom LK, Cameron JD, Erickson LA, Grimm TE. Severe periorbital edema secondary to imatinib mesylate for chronic myelogenous leukemia. Arch Ophthalmol. 2007;125(7):985-986.

16. Esmaeli B, Prieto VG, Butler CE, et al. Severe periorbital edema secondary to STI571 (Gleevec). Cancer. 2002;95(4):881-887.

17. Valeyrie L, Bastuji-Garin S, Revuz J, et al. Adverse cutaneous reactions to imatinib (STI571) in Philadelphia chromosome-positive leukemias: A prospective study of 54 patients. J Am Acad Dermatol. 2003;48(2): 201-206.

18. Pietras K, Ostman A, Sjoquist M, et al. Inhibition of plateletderived growth factor receptors reduces interstitial hypertension and increases transcapillary transport in tumors. Cancer Res. 2001;61(7): 2929-2934.

19. Druker BJ, Guilhot F, O'Brien SG, et al. IRIS Investigators. Five-year follow-up of patients receiving imatinib for chronic myeloid leukemia. N Engl J Med. 2006;355(23):2408-2417.

PubMed Central and CAS, and is the official journal of The Society of Clinical Ophthalmology (SCO). The manuscript management system is completely online and includes a very quick and fair peer-review system, which is all easy to use. Visit http://www.dovepress.com/ testimonials.php to read real quotes from published authors. 